\title{
Chronopharmacology of Furosemide in Rats with Amikacin- Induced Acute Renal Damage
}

\author{
Akio Fujimura, Tsuyoshi Shiga, Kyo-ichi Ohashi and Akio Ebihara \\ Department of Clinical Pharmacology, Jichi Medical School, Minamikawachi-machi, Kawachi-gun, Tochigi 329-04, Japan \\ Received April 22, 1992 Accepted August 1, 1992
}

\begin{abstract}
To examine the influcnce of amikacin-induced acute renal damage on the urinary excretion of furosemide and the time-dependent variation in the urinary amount of the agent, amikacin (1.2 $\mathrm{g} / \mathrm{kg}$ ) was given intraperitoneally to Wistar rats. Study I: Three percent b.w. of $1 \% \mathrm{NaCl}$ solution was given orally before and after amikacin treatment, and an 8-hour urine for $N$-acetyl- $\beta$-D-glucosaminidase (NAG) was collected. Study II: Furosemide $(30 \mathrm{mg} / \mathrm{kg})$ in $3 \%$ b.w. of $1 \% \mathrm{NaCl}$ solution was given orally at $12 \mathrm{a} . \mathrm{m}$. or $12 \mathrm{p} . \mathrm{m}$. before and after amikacin treatment, and an 8-hour urine for sodium and furosemide was collected. Following amikacin treatment, urinary excretion of NAG increased, whilc urine volume and urinary excretion of sodium and furosemide decreased. Urinary excretion of furosemide and its diuretic effects were significantly greater at $12 \mathrm{a} . \mathrm{m}$. than at $12 \mathrm{p} . \mathrm{m}$. before and after treatment. However the time-dependent differences in these parameters were diminished by amikacin treatment. These results suggest that the urinary excretion of furosemide is reduced and the extents of the time-dependent variation in the urinary furosemide and its diuretic effects are altered in rats with amikacin-induced renal damage.
\end{abstract}

Keywords: Chronopharmacology, Furosemide, Amikacin, Renal damage, Urinary NAG ( $N$-acetyl- $\beta$-D-glucosaminidase)

We have previously reported that the urinary excretion of furosemide, a loop diuretic agent, and its subsequent diuretic effects vary with the time of dosage in human subjects and animals $(1-3)$.

The aminoglycoside group of antibiotics is widely prescribed for the treatment of serious infections with gram negative bacteria. These agents can cause renal damage and lead to acute renal failure (ARF). Furosemide is frequently used to treat such patients, especially with an oliguric form of ARF (4). Furosemide is mainly excreted in urine by the organic anion transport system of the renal proximal tubule and thereafter, exerts its diuretic effects $(5,6)$. As aminoglycoside is taken up into the proximal tubular cells and causes damage to the tubular epithelium (7), it is suspected that renal tubular secretion of furosemide is impaired in patients with aminoglycoside-induced ARF. However, to our knowledge, no data are available concerning the influence of ARF induced by aminoglycoside on urinary excretion of furosemide. If this was the case, the chronopharmacological phenomenon of furosemide might also be influenced. To address these issues, the present study was undertaken to examine 1) whether the urinary excretion of furosemide is reduced in rats with amikacin (an aminoglycoside antibiotics)-induced ARF, and 2) whether the time-dependent variation in the urinary amount of furosemide is altered in these animals.

\section{MATERIALS AND METHODS}

Male Wistar rats (Charles River Laboratory, Kanagawa, Japan) weighing 300 to $350 \mathrm{~g}$ were maintained for more than 2 weeks under conditions of light from 7 a.m. to 7 p.m. and dark from 7 p.m. to 7 a.m. with free access to food and water.

The following two studies were done in the present study.

Study I: Twenty-two rats were divided into two groups. Sublethal dose of amikacin (7) $(1.2 \mathrm{~g} / \mathrm{kg}$ in $1 \mathrm{ml}$ of distilled water) was injected intraperitoneally (i.p.) to the 1 st group of rats $(n=11)$, while $1 \mathrm{ml}$ of vehicle alone was given i.p. to the 2 nd group of animals $(n=$ 11) on day 0 and again on day 7 . Threc percent body 
weight (b.w.) of $1 \% \mathrm{NaCl}$ solution was given by gavage into the stomach to these groups of rats on day -2 (control period), 2 and 9. Urine was collected for $8 \mathrm{hr}$ after each administration and urinary excretion of $\mathrm{N}$ acetyl- $\beta$-D-glucosaminidase (NAG) was determined. At the end of the experiment, blood samples were obtained under pentobarbital anesthesia.

Study II: Twenty-two rats were divided into two groups. In experiment A, 3\% b.w. of $1 \% \mathrm{NaCl}$ solution was given by gavage into the stomach at 12 a.m. (or 12 p.m.) to both groups of animals. Twenty-four hours after the vehicle, $30 \mathrm{mg} / \mathrm{kg}$ of furosemide in $3 \%$ b.w. of vehicle was given orally at $12 \mathrm{a} . \mathrm{m}$. (or $12 \mathrm{p} . \mathrm{m}$.). Urine was collected for $8 \mathrm{hr}$ following vehicle alone or the furosemide at $12 \mathrm{a} . \mathrm{m}$. (or 12 p.m.). Food and water were deprived during $8 \mathrm{hr}$ after each administration. The administration of the agent was randomly assigned to $12 \mathrm{a} . \mathrm{m}$. or $12 \mathrm{p} . \mathrm{m}$. The washout period between the two sets of trials was 7 days. Thereafter, $1.2 \mathrm{~g} / \mathrm{kg}$ of amikacin in $1 \mathrm{ml}$ of distilled water was injected i.p. to the 1st group of rats $(n=11)$, while $1 \mathrm{ml}$ of water was injected i.p. to the 2 nd group of animals $(n=11)$ on day 0 and again on day 7 (experiment $B$ ). The identical protocol of experiment $A$ was repeated (the vehicle alone study on days 1 and 8 and the furosemide study on days 2 and 9).

The activity of NAG in urine was determined by a colorimetric method (8). Urinary furosemide concentration was measured by high pressure liquid chromatography (9). Serum concentration of creatinine and blood urea nitrogen (BUN) and urinary concentration of sodium were determined by an autoanalyzer (736, Hitachi, Tokyo, Japan).

The results are expressed as the means \pm S.E. Data were analyzed by analysis of variance, and the paired or unpaired Student's $t$-test as appropriate.

\section{RESULTS}

Study I: Urinary excretion of NAG increased following amikacin on days 2 and 9 (Fig. 1). Serum BUN concentration in the amikacin-treated group was significantly greater than that in the vehicle-treated group. Serum creatinine concentration also was greater in the amikacin-treated animals, but the difference did not reach significance.

Study II: When 3\% b.w. of $\mathrm{NaCl}$ solution was given as a furosemide control, no significant difference was observed in urine volume or urinary sodium excretion in the collection period following the $12 \mathrm{a} . \mathrm{m}$. administration compared to the collection period beginning at 12 p.m. before (experiment A) and after (experiment B) the treatment with amikacin or its vehicle (Figs. 2 and 3).

Urinary furosemide excretion and its diuretic effects significantly decreased following treatment with amikacin (Fig. 3), but not vehicle (Fig. 2), both in the day and night trials. The $\%$ reduction in these parameters by amikacin treatment did not significantly differ between the day and night trials (urine volume: day trial, $0.27 \pm 0.06$; night trial, $0.23 \pm 0.12$; urinary sodium: day trial, $0.30 \pm 0.05$; night trial, $0.29 \pm 0.11$; and urinary furosemide: day trial, $0.48 \pm 0.09$; night trial, $0.40 \pm 0.08$ ). The values of urine volume and urinary excretions of sodium and furosemide were significantly greater at $12 \mathrm{a} . \mathrm{m}$. that at $12 \mathrm{p} . \mathrm{m}$. before (experiment A) and after (experiment B) treatment in the amikacinand vehicle-treated groups of rats. However the timedependent differences in these parameters were dimi-
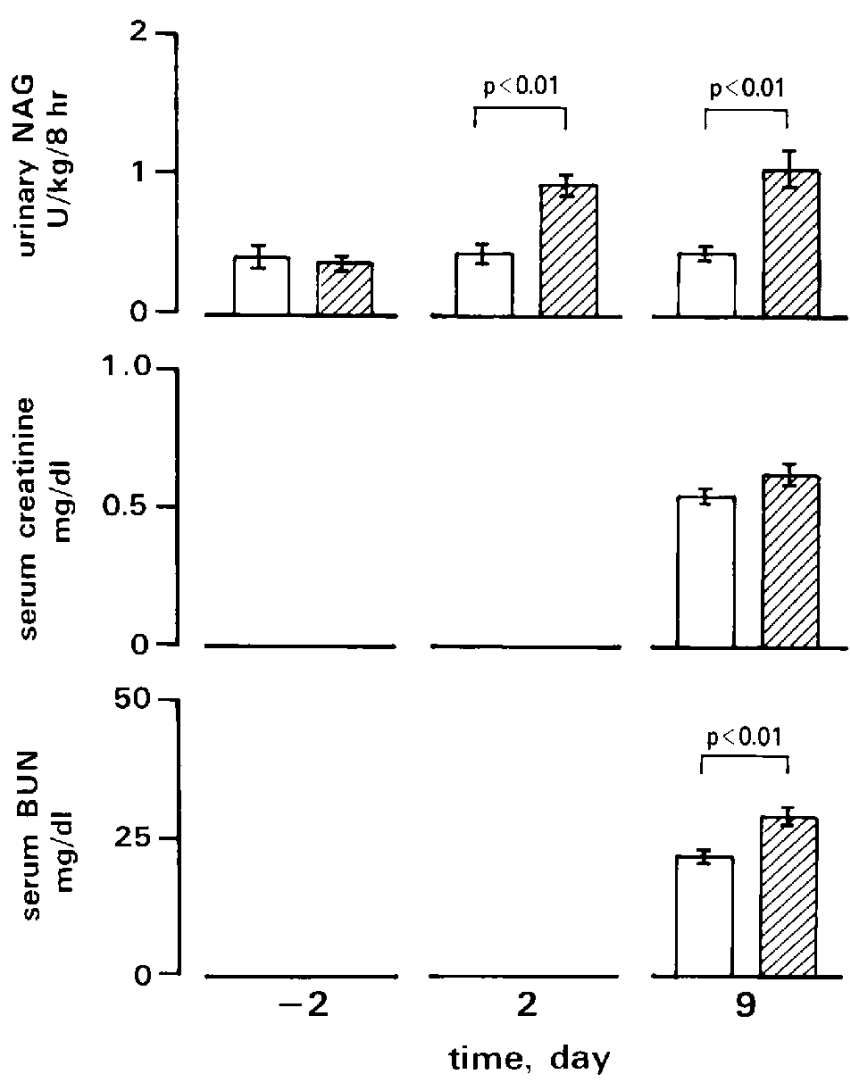

Fig. 1. Urinary excretion of NAG and serum concentrations of creatinine and BUN in rats treated with amikacin $(1.2 \mathrm{~g} / \mathrm{kg})$ or its vehicle (distilled water) on day 0 and again on day 7 . Mean \pm S.E. The open columns show data in the vehicle-treated rats $(\mathrm{n}=$ 11) and the shaded columns show data in the amikacin-treated animals $(\mathbf{n}=11)$. Three percent body weight of $1 \% \mathrm{NaCl}$ solution was given orally on days -2 (control period), 2 and 9 , and urine was collected for $8 \mathrm{hr}$ after administration. At the end of the experiment, blood samples were obtained under pentobarbital anesthesia. 
nished by amikacin treatment (Table 1). There were significant correlations between the urinary output of furosemide and its diuretic effects (urine volume and urinary sodium) in each study (Table 2 ). The regression

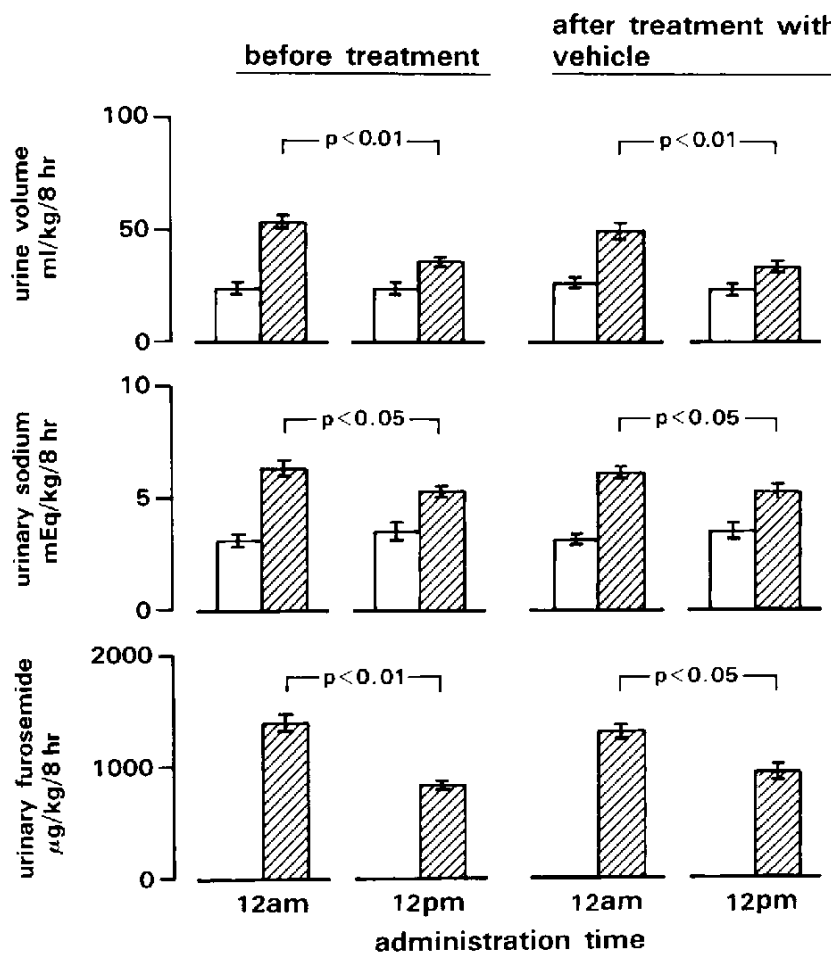

Fig. 2. Urine volume and urinary excretion of sodium and furosemide following furosemide $(30 \mathrm{mg} / \mathrm{kg}$ ) at $12 \mathrm{a} . \mathrm{m}$. or $12 \mathrm{p} . \mathrm{m}$. in the vehicle-treated rats. Mean \pm S.E. $n=11$. The open columns show data following $\mathrm{NaCl}$ solution alone and the shaded columns show data following $\mathrm{NaCl}$ solution + furosemide. lines between urinary furosemide and its effects did not significantly differ among experiments $\mathrm{A}$ and $\mathrm{B}$ in any group of animals.

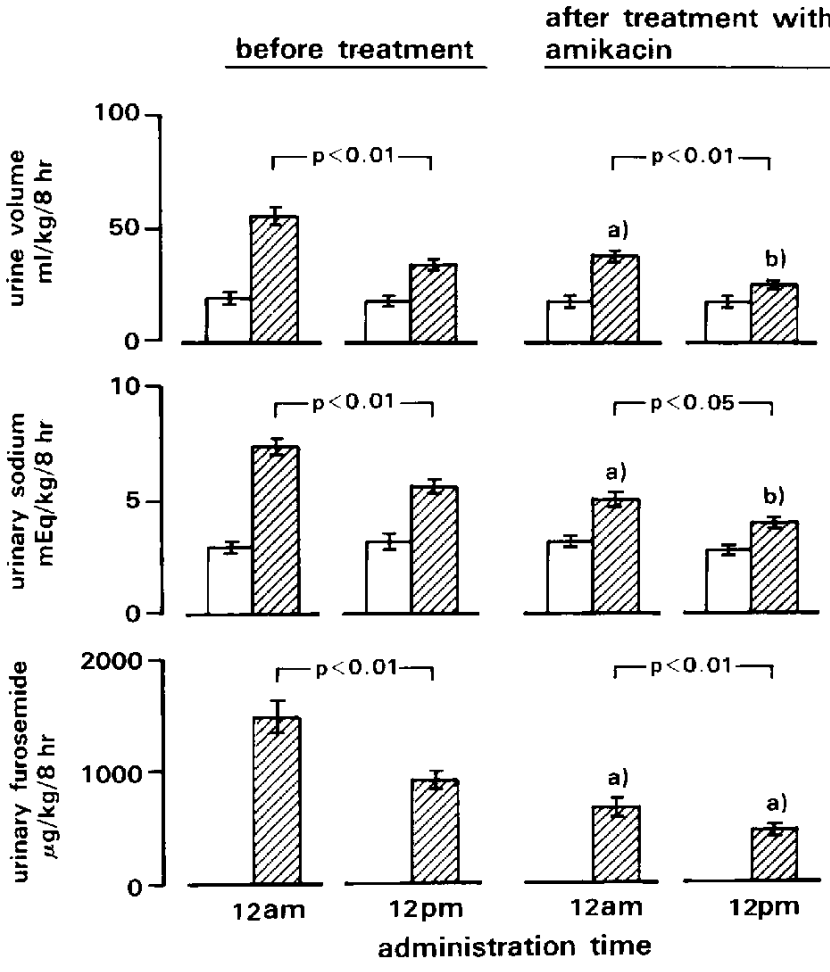

Fig. 3. Urine volume and urinary excretion of sodium and furosemide following furosemide $(30 \mathrm{mg} / \mathrm{kg}$ ) at $12 \mathrm{a} . \mathrm{m}$. or $12 \mathrm{p} . \mathrm{m}$. in the amikacin-treated rats. Mean \pm S.E. $n=11$. The open columns show data following $\mathrm{NaCl}$ solution alone and the shaded columns show data following $\mathrm{NaCl}$ solution + furosemide. ${ }^{\text {a) }}=\mathrm{P}$ $<0.01,{ }^{\text {b) }}=\mathrm{P}<0.05$, compared to the corresponding value during the control period (before treatment).

Table 1. Time-dependent difference in urine volume ( $\Delta$ UV) and urinary excretions of sodium ( $\Delta \mathrm{U}-\mathrm{Na}$ ) and furosemide ( $\Delta \mathrm{U}$-f) after furosemide administration in rats treated with amikacin or vehicle alone

\begin{tabular}{|c|c|c|c|c|}
\hline \multicolumn{2}{|c|}{ Group } & \multirow{2}{*}{$\begin{array}{c}\Delta \mathrm{UV}, \mathrm{ml} / \mathrm{kg} / 8 \mathrm{hr} \\
19.2 \pm 1.8\end{array}$} & \multirow{2}{*}{$\begin{array}{l}\Delta \mathrm{U}-\mathrm{Na}, \mathrm{mEq} / \mathrm{kg} / 8 \mathrm{hr} \\
1.2 \pm 0.2\end{array}$} & \multirow{2}{*}{$\frac{\Delta \mathrm{U}-\mathrm{f}, \mu \mathrm{g} / \mathrm{kg} / 8 \mathrm{hr}}{558 \pm 74}$} \\
\hline Vehicle-treated & before treatment & & & \\
\hline & after treatment & $17.5 \pm 3.3$ & $0.8 \pm 0.3$ & $391 \pm 105$ \\
\hline $\begin{array}{l}\text { Amikacin-treated } \\
(\mathrm{n}=11)\end{array}$ & $\begin{array}{l}\text { before treatment } \\
\text { after treatment }\end{array}$ & $\begin{array}{l}21.8 \pm 3.9 \\
12.0 \pm 2.7-\end{array}$ & $\begin{array}{l}2.0 \pm 0.3 \longrightarrow \text { P }<0.05 \\
1.0 \pm 0.2 \longrightarrow\end{array}$ & $\begin{array}{l}620 \pm 160 \square \\
212 \pm 58 \square 0.05\end{array}$ \\
\hline
\end{tabular}

Mean \pm S.E. $\quad \Delta U V(\mathrm{U}-\mathrm{Na}, \mathrm{U}-\mathrm{f})=\mathrm{UV}(\mathrm{U}-\mathrm{Na}, \mathrm{U}-\mathrm{f})$ in the day trial $-\mathrm{UV}(\mathrm{U}-\mathrm{Na}, \mathrm{U}-\mathrm{f})$ in the night trial 
Table 2. Relationship between urinary furosemide (U-f) and its diuretic effects [urine volume (UV) and urinary sodium (U-Na)] in rats treated with amikacin or vehicle alone

\begin{tabular}{|c|c|c|c|}
\hline \multicolumn{2}{|l|}{ Correlation } & \multirow{2}{*}{$\begin{array}{c}\text { Vehicle-treated }(\mathrm{n}=22) \\
y=0.026 x+14.6 \\
r=0.90(P<0.01)\end{array}$} & \multirow{2}{*}{$\begin{array}{l}\text { Amikacin-treated }(\mathrm{n}=22) \\
y=0.029 x+9.8 \\
r=0.95(P<0.01)\end{array}$} \\
\hline & before treatment & & \\
\hline U-f - UV & after treatment & $\begin{array}{l}y-0.027 x+7.8 \\
r=0.86(P<0.01)\end{array}$ & $\begin{array}{l}y=0.031 x+13.3 \\
r=0.64(P<0.01)\end{array}$ \\
\hline \multirow{2}{*}{$\mathrm{U}-\mathrm{f}-\mathrm{U}-\mathrm{Na}$} & bcfore treatment & $\begin{array}{l}y=0.0024 x+3.3 \\
r=0.89(P<0.01)\end{array}$ & $\begin{array}{l}y=0.0028 x+3.2 \\
r=0.90(P<0.01)\end{array}$ \\
\hline & after treatment & $\begin{array}{l}y=0.0(122 x+3.4 \\
r=0.87(P<0.01)\end{array}$ & $\begin{array}{l}y=0.0038 x+2.1 \\
r=0.68(P<0.01)\end{array}$ \\
\hline
\end{tabular}

\section{DISCUSSION}

Serum BUN concentration was significantly higher and serum creatinine concentration tended to be higher in the amikacin-treated rats than in the vehicle-treated animals on day 9 , which suggests that ARF was induced under the conditions of the present protocol. As the urinary NAG excretion significantly increased in the amikacin-treated rats on days 2 and 9 , it is speculated that the proximal tubular cells were damaged during these experimental days following $1.2 \mathrm{~g} / \mathrm{kg}$ of amikacin on day 0 and again on day 7 (7).

Urinary excretion of furosemide was reduced by treatment with amikacin in the present study. This might be due to the amikacin-induced damage of the renal proximal tubules which subsequently leads to the reduced secretion of furosemide. The present finding that the $\%$ reduction in urinary furosemide of the day and night trials did not significantly differ suggests that the degree of the inhibitory effect of amikacin on urinary furosemide in the day trial was similar to that in the night trial. On the other hand, an absorption of furosemide from the gastrointestinal tract is reported to be impaired in patients with renal failure (10). Therefore, it remains possible that the absorption of furosemide was blunted in the amikacin-treated rats which, in turn, led to the decreased excretion of the agent. Pharmacokinetic studies are needed to evaluate this hypothesis.

We have previously published data indicating that the urinary excretion of furosemide in the day trial is greatcr than that in the night trial in rats with intact kidncy $(2,3)$. These data are confirmed in the present study. Such a time-dependent variation in the urinary amount of furosemide also was observed in rats with amikacininduced renal damage. However, the absolute value of the time-dependent difference in this parameter was significantly reduced in these animals because the urinary excretion of furosemide decreased following amikacin treatment in the day and night trials. These findings suggest that the extent of the time-dependent variation in the urinary amount of furosemide is altered by a sublcthal dose of amikacin.

The time-dependent difference in the diuretic effects of furosemide also was significantly reduced in the amikacin-trcated rats. Significant correlations were observed between the urinary furosemide and its diuretic effects which is explained by the well-known concept that the diuretic effects of furosemide depend on its urinary amount (11). In addition, the regression lines between urinary furosemide and its diuretic effects after amikacin treatment did not significantly differ from those before treatment. This suggests that the responsiveness of renal tubular cells to furosemide is not disturbed in rats treated with $1.2 \mathrm{~g} / \mathrm{kg}$ of amikacin. This might be explained by the fact that amikacin causes the damage to the proximal tubular cells (7), while furosemide acts on the thick ascending limb of Henle's loop (5). Therefore, the reduction in the time-dependent difference in the diuretic effects of furosemide might, at least in part, depend on the reduction in the time-dependent difference in the urinary furosemide in rats with amikacin.

In summary, the present study suggests that the urinary excretion of furosemide is reduced and the extents of the time-dependent variation in the urinary amount of furosemide and its diuretic effects are altered in rats with amikacin-induced renal damage. 


\section{REFERENCES}

1 Tatcishi, T., Fujimura, A, Miura, T. and Ebihara, A.: Chronopharmacological study of furosemide in human subjects. Int. J. Chin. Pharm. Res. 6, $401-407$ (1988)

2 Fujimura, A. and Ebihara, A.: Chronopharmacological study of furosemide in rats. Life Sci. 38, 1215-1220 (1986)

3 Fujimura, A., Ohashi, K. and Ebihara, A.: Chronopharmacological study of furosemide; (VIII) influence of feeding restriction. Life Sci. 49, $1829-1834$ (1991)

4 Stein, J.H.: Acute renal failure. In Cecil, Textbook of Medicine, 16th edition, Edited by Wyngaarden, J.B. and Smith, L.H., p. 494-501, W.B. Saunders Company, Philadelphia (1982)

5 Weiner, I.M.: Diuretics and other agents employed in the mobilization of edema fluid. In The Pharmacological Basis of Therapeutics, Edited by Goodman Gilman, A., Rall, T.W. Nies, A.S. and Taylor, P., p. 713-731, Pergamon Press, New York (1990)

6 Van Ginneken, C.A.M. and Russel, F.G.M.: Saturable phar- macokinetics in the renal excretion of drugs. Clin. Pharmacokinet. 16, 38-54 (1989)

7 Cal, J.C., Dorian, C. and Camber, J.: Circadian and circannual changes in nephrotoxic effects of heavy metals and antibiotics. In Annual Review of Chronopharmacology, Vol. 2, Edited by Reinberg, A., Smolensky, M. and Labrecque, G., p. 143 - 176, Pergamon Press, New York (1986)

8 Maruhn, D.: Rapid colorimetric assay of $\beta$-galactosidase and $N$-acetyl- $\beta$-glucosaminidase in human urine. Clin. Chim. Acta 73, $453-461$ (1976)

9 MacDougall, M.L., Shoeman, D.W. and Azarnoff, D.L.: Separation and quantitative analysis of furosemide and 4chloro-5-sulfamoylanthranilic acid (CSA) by high pressure liquid chromatography. Res. Commun. Chem. Pathol. Pharmacol. 10, $285-292$ (1975)

10 Tilstone, W.J. and Fine, A.: Furosemide kinetics in renal failure. Clin. Pharmacol. Ther. 23, 644-650 (1978)

11 Odlind, B. and Beermann, B.: Renal tubular secretion and effects of furosemide. Clin. Pharmacol. Ther. 27, 784-790 (1980) 